\title{
Relationship of Depression, Anxiety, and Stress (DASS-21), Saliva Cortisol Levels, Platelet- Lymphocyte Ratio with Severity in COVID-19
}

\author{
Erik Jaya Gunawan ${ }^{a}$, Arie Utariani ${ }^{a *}$, Margarita M. Maramis ${ }^{b}$ \\ aDepartment of Anesthesiology and Reanimation, Faculty of Medicine, Universitas Airlangga, \\ Surabaya, 60286, Indonesia. \\ bepartment of Psychiatry, Faculty of Medicine, Universitas Airlangga, Surabaya, 60286, \\ Indonesia. \\ *Corresponding Author: arie.utariani@fk.unair.ac.id
}

\begin{abstract}
Background: COVID-19 causes physical and psychological stressors. The aim of this study is to analyze the relationship of depression, anxiety, stress levels (DASS-21), salivary cortisol, and platelet-lymphocyte ratio (PLR) with severity in COVID-19 patients.

Methods: This is a cohort prospective study. Inclusion criteria were new patient at isolation room of Dr. Soetomo Hospital Surabaya with a confirmed COVID-19, 21-60 years, could answer a questionnaire. Measurements of DASS-21, salivary cortisol levels (at 7-9 a.m), PLR, and severity were carried out on day- 0,3 , and 6 during hospitalization. Bivariate and multivariate (logistic regression) analyses were conducted to assess the relationship between variables.

Results: 46 subjects were included in this study. On day-0, there were $34.8 \%$ subjects with very severe levels of anxiety. DASS-21 score and PLR decreased significantly on day-3 and 6 . The anxiety $(\mathrm{p}=0.002)$, lymphocyte $(\mathrm{p}=0.000), \operatorname{PLR}(\mathrm{p}=0.000)$, and salivary cortisol levels $(\mathrm{p}=0.032)$ were significantly different between the mild-moderate and severe group on day-0. In severe group, lymphocyte and salivary cortisol levels were lower than the mild-moderate group. On day-3, depression $(\mathrm{p}=0.021)$, anxiety $(\mathrm{p}=0.001)$, lymphocyte $(\mathrm{p}=0.025)$, and PLR $(\mathrm{p}=0.005)$ were significantly different between mild-moderate and severe group. In multivariate analysis, PLR on days 0 and 3 (respectively $\mathrm{OR}=1.015, \mathrm{p}=0.012$ and $\mathrm{OR}=1.010, \mathrm{p}=0.013$ ) and anxiety level on day-3 (OR=1.225, $\mathrm{p}=0.019)$ had a significant effect on the severity of COVID-19.

Conclusion: Salivary cortisol was lower in the severe group on day 0. PLR on day-0 and 3 and anxiety level on day 3 were independent factors related to the severe case. Improvements in all variables were followed by decreasing COVID-19 severity.
\end{abstract}

Keywords: COVID-19, depression, anxiety, stress, cortisol, platelet-lymphocyte ratio, severity.

\section{INTRODUCTION}

Covid-19 pandemic has impacted more than 200 countries in the world. A person diagnosed with COVID-19 experiences stress, both physically and psychologically. Stressor is defined as any form of trauma, surgery, and infection that evokes a large number of neural and hormonal responses, resulting in disruption of the homeostatic mechanism of the patient, which aims to maintain and bring the patient to the healing process ${ }^{1}$. The main neuroendocrine response to stressor is the Hypothalamic - Pituitary - Adrenal (HPA) axis ${ }^{2}$. Responses to stressors vary depending on the individual (genes, previous experiences, growth and development processes) and the perspective on these stressors resulting in behavioral and 
physiological responses ${ }^{3}$. Stress conditions that are not handled properly can have a negative impact. Increased in psychological stress is associated with mortality 4,5 .

Clinically, stressors can cause symptoms of anxiety, fear of certain contexts, anhedonic and dysphoric, angry and aggressive, or dissociative ${ }^{6}$. Symptoms of anxiety, depression, related to psychological stress were found in COVID-19 patients who were treated in isolation rooms. In a study conducted in Wuhan, patients in isolation rooms experienced depression, anxiety, and insomnia ${ }^{7}$. In Italy, patients undergoing isolation experience problems with an increased risk of mental disorders, such as anxiety, mood, and addiction ${ }^{8}$.

When a stressor is detected and the signal is picked up by the central nervous system, it results in activation of the HPA and Sympathetic Nervous System (SNS) axis, and subsequent inflammatory, immune, and behavioral changes. Corticotropin-releasing hormone (CRH), released by the hypothalamus, stimulates the release of adrenocorticotropin hormone (ACTH) from the anterior pituitary in the bloodstream, and the adrenal glands produce cortisol: hence the name stress hormone. HPA is regulated by a negative feedback mechanism in which cortisol suppresses CRH and ACTH secretion ${ }^{1}$. The adrenal glands do not store cortisol, the increased secretion is due to increased synthesis under the influence of ACTH. More than $90 \%$ of circulating cortisol is bound to Corticotropin Binding Globulin (CBG) and less than $10 \%$ is free and biologically active. This free cortisol is more accurate in describing the mechanism of the HPA axis. Variations in CBG, albumin, and serum protein levels will not affect free cortisol ${ }^{2}$. Salivary cortisol has an equilibrium value with serum free cortisol levels ${ }^{9}$. Salivary cortisol reaches equilibrium within 2-3 minutes. Sampling is more convenient, non-invasive, nonstressful, and measurements can be made ${ }^{9,10}$.

SARS-CoV-2 virus infection causes excessive production of proinflammatory cytokines, called cytokine storm that affects the hematology and immune system, especially neutrophils, $\mathrm{T}$ lymphocyte, and platelet ${ }^{11,12}$. Stress conditions and elevated cortisol can also affect lymphocytes and platelets. Cortisol causes lymphocytes to age more quickly. Aging T lymphocyte cells cannot respond to stimulation from antigens to differentiate and proliferate, so the ability to overcome infection will also decrease ${ }^{13,14}$. Epinephrine released during stress causes platelet activation and increases serotonin binding to its receptors, which in turn increases the activation of other platelets in thrombus formation ${ }^{15}$. Both parameters (platelets and lymphocytes) in the form of the Platelet-Lymphocyte ratio (PLR) can show a correlation with mood disorders and post-stroke depression. This is associated with the inflammatory mechanism underlying these psychological disorders ${ }^{16,17}$. Based on these previous studies, the PLR is expected to describe the inflammatory and stressful conditions experienced by COVID-19 patients.

The aim of this study is to analyze the relationship between depression, anxiety, and stress levels, cortisol levels and the work of the immune system in COVID-19 patients. This study is expected to provide a better pathophysiological description of the stressful conditions experienced, routine laboratory examinations that can describe the patient's condition, and its effect on patient severity. With a better understanding of the stress factors experienced by 
patients, interventions for related factors can be applied to improve conditions and reduce mortality rates in COVID-19.

\section{METHOD}

This is a cohort prospective study. Ethical clearance was issued by Health Research Ethics Committee Dr. Soetomo Hospital Surabaya, Indonesia. Study was conducted from May to July 2021 in Dr. Soetomo Hospital Surabaya. Sampling technique was consecutive random sampling. All COVID-19 patients, who were hospitalized in the Isolation Room and fulfilled the inclusion criteria, were included in this study. Inclusion criteria were: age $21-60$ years old, new patients with confirmed COVID-19 diagnosis and admitted to the Isolation Room, could communicate orally and are able to answer questionnaires (without endotracheal intubation), and agreed to be the subject of this study. Exclusion criteria were patient with severe cognitive deficits, trauma or undergoing surgery, pregnancy or the puerperium, history of autoimmune disease or taking steroids and immunosuppressants before, HIV infection, malignancy or undergoing chemotherapy, previously been treated in another isolation room for 7 days or more. Drop out criteria were withdrew from research, refuse further treatment, or died before $3^{\text {rd }}$ day of hospitalization.

New patients admitted to the isolation room were explained about this study. If they agreed to be a subject in this study, the patient signed an informed consent. Age, BMI, comorbidities, and level of education were recorded in this study. Levels of depression, anxiety, stress, salivary cortisol, PLR, and COVID-19 severity were assessed periodically on days-0, 3, and 6. This measure was based on the stress response period experienced by the patient, namely the ebb/ shock/ alarm reaction phase in the first 24 hours after exposure to stressor and flow/ resistance/ contra-shock phase at 6-7 days after exposure to stressor ${ }^{1,18}$. Stressors in this study were defined as confirmed COVID-19 diagnosis and hospitalization in isolation room. Subjects who were allowed to leave the isolation room (self-isolation) or had a worsening condition (require mechanical ventilation) between days- 3 and 6 were still included in the study and were given special notes. All patients received therapy according to practical guidelines in Dr. Soetomo hospital Surabaya (which included dexamethasone $6 \mathrm{mg}$ intravenous once daily for 10 days).

Levels of depression, anxiety, and stress were measured using the Depression, Anxiety, and Stress (DASS)-21 questionnaire in Bahasa Indonesia. The DASS-21 was developed by researchers at the University of New South Wales Australia ${ }^{19}$. This is a self-report questionnaire with Likert-type answers ranging from 0 to $3(0=$ did not apply to me at all, $1=$ applied to me to some degree, or some of the time, $2=$ applied to me to considerable degree, or a good part of time, 3 = applied to me very much, or most of the time), consisting of three components to measure negative emotional states of depression, anxiety and stress. The sensitivity and specificity of this questionnaire in diagnosing depression and anxiety were $79.1 \%$ and $77 \%$, respectively ${ }^{20}$. The DASS-21 questionnaire in Bahasa Indonesia has good internal consistency 
(the Cronbach Alpha formula of 0.9483) ${ }^{21}$. In this study, the questionnaire was modified every 3 day.

Salivary cortisol levels were measure using Cortisol Enzyme Immunoassay Kit (Salimetrics@). Saliva (1-2 ml) was collected at 7-9 a.m on day 0, 3, and 6. Whole saliva was collected by unstimulated passive drool. Patients put the saliva into a polypropylene vial. After collection, sample was refrigerated for 30 minutes, and frozen at below $-20^{\circ} \mathrm{C}$. On day of assay, the saliva samples were thawed completely, vortex, and centrifuged at $1500 \mathrm{x} \mathrm{g}$ for 15 minutes to remove mucins and other particulate matter which may interfere with antibody binding and affect results. Samples should be at room temperature before adding to assay plate. The clear sample was pippeted into a suitable well. Cortisol in standards and samples compete with Cortisol conjugated to horseradish peroxidase for the antibody binding sites on a microtitre plate. After incubation, unbound components are washed away. Bound Cortisol Enzyme Conjugate is measured by the reaction of the horseradish peroxidase enzyme to the substrate tetramethylbenzidine (TMB). This reaction produces a blue color. A yellow color is formed after stopping the reaction with an acidic solution. The optical density is read on a standard plate reader at $450 \mathrm{~nm}$. The amount of Cortisol Enzyme Conjugate detected is inversely proportional to the amount of Cortisol present in the sample. Normal range in this study $0.094-1.551 \mu \mathrm{g} / \mathrm{dl}$ 22 .

Platelet and lymphocyte levels were measured from venous blood. 2-3 $\mathrm{ml}$ of venous blood was drawn using a sterile disposable syringe on day 0,3 , and 6 . The blood sample was put into a tube that already contained EDTA Darah sebanyak 2-3 ml dimasukkan ke dalam tabung yang telah diberi EDTA. The sample was subjected to a complete blood count using a Sysmex $\mathrm{XN}-3000$ hematology analyzer machine.

COVID-19 severity was classified using WHO criteria. Mild disease: symptomatic patients meeting the case definition for COVID-19 without evidence of viral pneumonia or hypoxia. Moderate disease: Adolescent or adult with clinical signs of pneumonia (fever, cough, dyspnoea, fast breathing) but no signs of severe pneumonia, including $\mathrm{SpO} 2 \geq 90 \%$ on room air. Severe disease: Adolescent or adult with clinical signs of pneumonia (fever, cough, dyspnoea, fast breathing) plus one of the following: respiratory rate $>30$ breaths/min; severe respiratory distress; or $\mathrm{SpO} 2<90 \%$ on room air. Critical disease: Acute Respiratory Distress Syndrome (ARDS), Sepsis, Septic shock, or other complications that have been described in COVID-19 patients include acute, life-threatening conditions such as: acute pulmonary embolism, acute coronary syndrome, acute stroke and delirium. Clinical suspicion for these complications should be heightened when caring for COVID-19 patients, and appropriate diagnostic and treatment protocols available ${ }^{23}$.

Demographic data and all variables are presented in descriptive statistics. The data presents in the form of Mean \pm SD for data with normal distribution and Median (range) for data not normally distributed. Comparative test (Related-Samples Friedman's Two-Way Analysis Of Variance by Ranks or Reapeted ANOVA) was conducted to determine the significance of the differences of the variables at each measurement time (day-0, 3, and 6). Variables were 
processed using univariate and multivariate statistical analysis. Severity COVID-19 was classified into two categories, mild-moderate group and severe group. Univariate analysis was performed to compare various variables according to the type of data (Independent-Samples Median Test, or paired T-Test). Variable associated with $\mathrm{p}<0.05$ on univariate analysis were included in the multivariate analysis. The multivariate analysis was performed using a logistic regression model, with a stepwise backward elimination procedure, to determine variables that contribute to severe disease in COVID- 19 patients. That variable presented as odds ratios, including $95 \%$ confidence intervals. IBM SPSS Statistic version 23.0 was used for all analysis.

\section{RESULT}

There were 46 subjects met the inclusion critera. Majority of subjects was overweight and obesity (52.3\%). Mortality in this study was $2.2 \%$.

Table 1. Characteristics of Subjects.

\begin{tabular}{|l|c|c|c|}
\hline \multicolumn{1}{|c|}{ Characteristics } & $\mathbf{N}(\%)$ & Mean \pm SD & Median (IQR) \\
\hline Sex & & & \\
\hline Male & $26(56.5 \%)$ & & \\
\hline Female & $20(43.5 \%)$ & & \\
\hline Education levels & & & \\
\hline $\begin{array}{l}\text { Elementary } \\
\text { school }\end{array}$ & $9(19.6 \%)$ & & \\
\hline Junior high school & $4(8.7 \%)$ & & \\
\hline Senior high school & $23(50.0 \%)$ & & $25.1(18.3-52.0)$ \\
\hline Undergraduate & $10(21.7 \%)$ & & \\
\hline Age (years) & & $41.6 \pm 11.4$ & \\
\hline BMI (kg/m $\left.{ }^{2}\right)$ & $22(47.8 \%)$ & & \\
\hline Normal (18.0-24.9) & $22.0 \pm 5.8$ & \\
\hline $\begin{array}{l}\text { Overweight and obesity } \\
(\geq 25.0)\end{array}$ & $24(52.2 \%)$ & & \\
\hline Comorbidities & & & \\
\hline Hypertension & $8(17.4 \%)$ & & \\
\hline Diabetes mellitus & $9(19.6 \%)$ & & \\
\hline Mortality & $1(2.2 \%)$ & & \\
\hline
\end{tabular}

All variables (table 2.) had significant changes on day-0, 3, and 6. Majority of subject experienced anxiety. On day-6, 30 subjects left. The condition of 16 subjects improved. They were allowed to self-isolate. On day-0, there were $34.8 \%$ subjects with very severe levels of anxiety. Depression, anxiety, and stress level decreased significantly on day-3 and 6. Platelet and 
lymphocyte increased on day-3 and 6. PLR decreased significantly on day-3 and 6. Median of Salivary cortisol level was lowest on day-3.

Table 2. Median (IQR) Depression, Anxiety, and Stress Level (DASS-21) on Day-0, 3, and 6

\begin{tabular}{|c|c|c|c|c|}
\hline & \multicolumn{3}{|c|}{ Day } & \multirow[b]{3}{*}{$\mathbf{p}$} \\
\hline & 0 & 3 & 6 & \\
\hline & $\begin{array}{c}N(\%) \\
46(100.0)\end{array}$ & $\begin{array}{c}\mathrm{N}(\%) \\
46(100.0)\end{array}$ & $\begin{array}{c}\mathbf{N}(\%) \\
30(100.0)\end{array}$ & \\
\hline Depresi - Median (range) & $4.0(0.0-20.0)$ & $2.0(0.0-14.0)$ & $0.0(0.0-12.0)$ & $0.000^{*}$ \\
\hline Normal - N(\%) & $37(80.4 \%)$ & $43(93.5 \%)$ & $29(96.7 \%)$ & \\
\hline Mild & $5(10.9 \%)$ & $2(4.3 \%)$ & $1(3.3 \%)$ & \\
\hline Moderate & $4(8.7 \%)$ & $1(2.2 \%)$ & - & \\
\hline Severe & - & - & - & \\
\hline Very Severe & - & - & - & \\
\hline Ansietas - Median (range) & $12.0(0.0-36.0)$ & $11.0(0.0-28.0)$ & $4.0(0.0-26.0)$ & $0.000 *$ \\
\hline Normal & $12(26.1 \%)$ & $19(41.3 \%)$ & $20(66.7 \%)$ & \\
\hline Mild & $3(6.5 \%)$ & - & $2(6.7 \%)$ & \\
\hline Moderate & $12(26.1 \%)$ & $13(28.3 \%)$ & $2(6.7 \%)$ & \\
\hline Severe & $3(6.5 \%)$ & $7(15.2 \%)$ & $3(10.0 \%)$ & \\
\hline Very Severe & $16(34.8 \%)$ & $7(15.2 \%)$ & $3(10.0 \%)$ & \\
\hline Stres - Median (range) & $2.0(0.0-20.0)$ & $3.0(0.0-18.0)$ & $1.0(0.0-12.0)$ & 0.036* \\
\hline Normal & $44(95.7 \%)$ & $44(95.7 \%)$ & $30(100.0 \%)$ & \\
\hline Mild & - & $2(4.3 \%)$ & - & \\
\hline Moderate & $2(4.3 \%)$ & - & - & \\
\hline Severe & - & - & - & \\
\hline Very Severe & - & - & - & \\
\hline Platelet $\left(10^{3} / \mu \mathrm{l}\right)-$ Mean \pm SD & $291.3 \pm 109.0$ & $360.0 \pm 128.6$ & $417.0 \pm 135.8$ & $0.000 \dagger$ \\
\hline $\begin{array}{l}\text { Lymphocyte }\left(10^{3} / \mu \mathrm{l}\right)- \\
\text { Median (range) }\end{array}$ & $\begin{array}{c}1.085 \\
(0.550-3.880)\end{array}$ & $\begin{array}{c}1.275 \\
(0.500-2.680)\end{array}$ & $\begin{array}{c}1.665 \\
(0.990-3.890)\end{array}$ & $0.000 *$ \\
\hline PLR - Median (range) & $\begin{array}{c}247.5 \\
(69.9-555.3)\end{array}$ & $\begin{array}{c}233.0 \\
(94.7-1,063.6)\end{array}$ & $\begin{array}{c}207.0 \\
(105.0-478.5)\end{array}$ & $0.019 *$ \\
\hline $\begin{array}{l}\text { Salivary cortisol }(\mathrm{mcg} / \mathrm{dl})- \\
\text { Median (range) }\end{array}$ & $\begin{array}{c}0.230 \\
(0.023-1.488)\end{array}$ & $\begin{array}{c}0.170 \\
(0.021-1.428)\end{array}$ & $\begin{array}{c}0.242 \\
(0.085-1.265) \\
\end{array}$ & $0.004 *$ \\
\hline
\end{tabular}

*Related-Samples Friedman's Two-Way Analysis Of Variance by Ranks; †Repeated ANOVA

Table 3, 4, and 5 show the differences of the depression, anxiety, stress levels, platelet, lymphocyte, PLR and salivary cortisol levels in the mild-moderate and severe severity groups on day-0, 3, and 6 .

Table 3. Univariate Analysis of day-0

\begin{tabular}{|l|c|c|c|}
\hline \multirow{2}{*}{} & \multicolumn{2}{|c|}{ Severity } & \multirow{2}{*}{ P } \\
\cline { 2 - 3 } & Mild-moderate & Severe & \\
\cline { 2 - 3 } & $\mathbf{N = 2 7 ( 5 8 . 7 \% )}$ & $\mathbf{N = 1 9 ( 4 1 . 3 \% )}$ & \\
\hline DASS-21 - Median (range) & & & \multirow{2}{*}{$0.692^{*}$} \\
\hline Depression score & $2.0(0.0-14.0)$ & $4.0(0.0-20.0)$ & $\mathbf{0 . 0 0 2}^{*}$ \\
\hline Anxiety score & $10.0(0.0-30.0)$ & $20.0(4.0-36.0)$ & \\
\hline
\end{tabular}




\begin{tabular}{|l|c|c|c|}
\hline \multicolumn{1}{|c|}{ Stress score } & $2.00(0.0-20.0)$ & $2.00(0.0-12.0)$ & $0.566^{*}$ \\
\hline Platelet $\left(10^{3} / \mu \mathrm{l}\right)-$ Mean \pm SD & $275.2 \pm 95.6$ & $314.2 \pm 124.6$ & $0.236^{\dagger}$ \\
\hline Lymphocyte $\left(10^{3} / \mu \mathrm{l}\right)-$ Median (range) & $1.215(0.650-3.880)$ & $0.870(0.550-1.410)$ & $\mathbf{0 . 0 0 0}^{*}$ \\
\hline PLR - Mean $\pm \mathrm{SD}$ & $217.6 \pm 74.6$ & $350.2 \pm 119.9$ & $\mathbf{0 . 0 0 0}^{\dagger}$ \\
\hline Salivary Cortisol $(\mu \mathrm{g} / \mathrm{dl})-$ Median (range) & $0.328(0.087-1.488)$ & $0.193(0.023-0.665)$ & $\mathbf{0 . 0 3 2}^{*}$ \\
\hline
\end{tabular}

*Independent-Samples Median Test; "paired T-test

There were significant differences between the mild-moderate and severe group in the anxiety level, lymphocyte levels, PLR, and salivary cortisol levels. In the group with severe group, lymphocyte and salivary cortisol levels were lower than the mild-moderate group.

Table 4. Univariate Analysis of day-3

\begin{tabular}{|c|c|c|c|}
\hline & \multicolumn{2}{|c|}{ Severity } & \multirow{3}{*}{$\mathbf{P}$} \\
\hline & Mild-moderate & Severe & \\
\hline & $\mathrm{N}=30(65.2 \%)$ & $\mathrm{N}=16(34.8 \%)$ & \\
\hline \multicolumn{4}{|l|}{ DASS-21 - Median (range) } \\
\hline Depression score & $0.0(0.0-8.0)$ & $4.0(0.0-14.0)$ & 0.021* \\
\hline Anxiety score & $6.0(0.0-18.0)$ & $14.0(4.0-28.0)$ & 0.001* \\
\hline Stress score & $2.0(0.0-14.0)$ & $4.0(0.0-16.0)$ & $0.122 *$ \\
\hline Platelet $\left(10^{3} / \mu \mathrm{l}\right)-$ Mean \pm SD & $292.2 \pm 92.7$ & $289.5 \pm 137.9$ & $0.937 \dagger$ \\
\hline Lymphocyte $\left(10^{3} / \mu \mathrm{l}\right)-$ Median (range) & $1.500(0.830-2.680)$ & $0.950(0.500-1.870)$ & $0.025 *$ \\
\hline PLR - Mean \pm SD & $219.5(108.0)$ & $435.1(313.0)$ & $0.005 *$ \\
\hline Salivary Cortisol $(\mu \mathrm{g} / \mathrm{dl})$ - Median (range) & $0.139(0.021-2.853)$ & $0.206(0.027-1.428)$ & $0.460 *$ \\
\hline
\end{tabular}

*Independent-Samples Median Test; ${ }^{\dagger}$ paired T-test

There were significant differences between the mild-moderate and severe group on day-3 in the depression, anxiety level, lymphocyte levels, and PLR. In the group with severe group, lymphocyte level was lower than the mild-moderate group.

Table 5. Univariate Analysis of day-6

\begin{tabular}{|c|c|c|c|}
\hline & \multicolumn{2}{|c|}{ Severity } & \multirow{3}{*}{$\mathbf{P}$} \\
\hline & Mild-moderate & Severe & \\
\hline & $\mathrm{N}=27(90.0 \%)$ & $\mathrm{N}=3(\mathbf{1 0 . 0 \% )}$ & \\
\hline \multicolumn{4}{|l|}{ DASS-21 - Median (range) } \\
\hline Depression score & $0.0(0.0-12.0)$ & $2.0(2.0-8.0)$ & $0.016 *$ \\
\hline Anxiety score & $4.0(0.0-22.0)$ & $22.0(2.0-26.0)$ & $0.320 *$ \\
\hline Stress score & $0.0(0.0-12.0)$ & $4.0(0.0-4.0)$ & $0.543 *$ \\
\hline Platelet $\left(10^{3} / \mu \mathrm{l}\right)-$ Mean \pm SD & $422.0(146.0-645.0)$ & $531.0(385.0-613.0)$ & $0.543 *$ \\
\hline Lymphocyte $\left(10^{3} / \mu \mathrm{l}\right)$ - Median (range) & $1.730(1.030-3.890)$ & $1.470(0.990-2.220)$ & $0.543 *$ \\
\hline PLR - Median (range) & $187.2(105.0-478.5)$ & $361.2(276.1-388.9)$ & $0.068 *$ \\
\hline Salivary Cortisol $(\mu \mathrm{g} / \mathrm{dl})$ - Median (range) & $0.245(0.085-1.265)$ & $0.160(0.101-0.327)$ & $0.543 *$ \\
\hline
\end{tabular}

*Independent-Samples Median Test 
There was significant difference between the mild-moderate and severe group on day- 6 in the depression score. Result on day- 6 was not included in multivariate analysis.

All variables were grouped into decreased, fixed, and increased to analyze changes during treatment and their effect on changes in the COVID-19 severity. Changes were obtained from the difference in measurements on day 0 and 6. 
Table 6. Distribution Frequency The Changes of DASS-21 score, Platelet, Lymphocyte, PLR, and COVID-19 Severity on day-0 and 6

\begin{tabular}{|c|c|c|c|c|}
\hline & & rity & Total & P* \\
\hline & Improve & Fixed or worse & Iotal & P* \\
\hline DASS-21 & & & & \\
\hline Depression s & & & & \\
\hline Decrease & $12(40.0 \%)$ & $8(26.7 \%)$ & $20(66.7 \%)$ & \\
\hline Fixed & $4(13.3 \%)$ & $3(10.0 \%)$ & $7(23.3 \%)$ & 1.000 \\
\hline Increase & $2(6.7 \%)$ & $1(3.3 \%)$ & $3(10.0 \%)$ & \\
\hline Anxiety scor & & & & \\
\hline Decrease & $16(53.3 \%)$ & $7(23.3 \%)$ & $23(76.7 \%)$ & \\
\hline Fixed & $0(0.0 \%)$ & $1(3.3 \%)$ & $1(3.3 \%)$ & 0.099 \\
\hline Increase & $2(6.7 \%)$ & $4(13.3 \%)$ & $6(20.0 \%)$ & \\
\hline Stress score & & & & \\
\hline Decrease & $10(33.3 \%)$ & $7(23.3 \%)$ & $17(56.7 \%)$ & \\
\hline Fixed & $2(6.7 \%)$ & $2(6.7 \%)$ & $4(13.3 \%)$ & 1.000 \\
\hline Increase & $6(20.0 \%)$ & $3(10.0 \%)$ & $9(30.0 \%)$ & \\
\hline Platelet & & & & \\
\hline Decrease & $5(16.7 \%)$ & $2(6.7 \%)$ & $7(23.3 \%)$ & 0669 \\
\hline Increase & $13(43.3 \%)$ & $10(33.3 \%)$ & $23(76.7 \%)$ & 0.009 \\
\hline Lymphocyt & & & & \\
\hline Decrease & $2(6.7 \%)$ & $4(13.3 \%)$ & $6(20.0 \%)$ & 0184 \\
\hline Increase & $16(53.3 \%)$ & $8(26.7 \%)$ & $24(80.0 \%)$ & 0.184 \\
\hline PLR & & & & \\
\hline Decrease & $14(46.7 \%)$ & $6(20.0 \%)$ & $20(66.7 \%)$ & 0120 \\
\hline Increase & $4(13.3 \%)$ & $6(20.0 \%)$ & $10(33.3 \%)$ & 0.139 \\
\hline Salivary Co & & & & \\
\hline Decrease & $10(33.3 \%)$ & $9(30.0 \%)$ & $19(63.3 \%)$ & \\
\hline Increase & $8(26.7 \%)$ & $3(10.0 \%)$ & $11(36.7 \%)$ & 0.442 \\
\hline
\end{tabular}

*Fisher's Exact Test

There were not any significant relationship between changes of DASS-21 score, platelet, lymphocyte, PLR, and salivary cortisol with COVID-19 severity. However, improvements in all variables were in line with the decreasing severity of COVID-19.

These are multivariate analysis of variables that contribute to severe disease in COVID19 day -0 and 3 (table 7 ). 
Table 7. Multivariate analysis variable on day- 0 and 3

\begin{tabular}{|l|c|c|c|c|}
\hline & Coefficient & Odds Ratio (OR) & $\mathbf{9 5 \%}$ CI & p \\
\hline Day-0 & & & & \\
\hline Anxiety Level & 0.065 & 1.068 & $0.967-1.179$ & 0.196 \\
\hline Salivary Cortisol & -3.558 & 0.029 & $0.000-1.850$ & 0.095 \\
\hline Lymphocyte & -0.003 & 0.997 & $0.994-1.000$ & 0.056 \\
\hline PLR & 0.015 & 1.015 & $1.003-1.026$ & $\mathbf{0 . 0 1 2}$ \\
\hline Constant & 0.067 & & & \\
\hline R-Square & $62.9 \%$ & & & \\
\hline Day-3 & & & & $0.905-1.845$ \\
\hline Depression Level & 0.257 & 1.293 & $1.044-1.436$ & $\mathbf{0 . 0 1 3}$ \\
\hline Anxiety Level & 0.203 & 1.010 & $0.996-1.001$ & 0.308 \\
\hline Lymphocyte & -0.001 & 0.999 & $1.002-1.019$ & $\mathbf{0 . 0 1 9}$ \\
\hline PLR & 0.010 & 1.225 & & \\
\hline Constant & -6.189 & & & \\
\hline R-Square & $63.0 \%$ & & & \\
\hline
\end{tabular}

On day-0, PLR had a significant influence on the incidence of severe COVID-19 (OR $(95 \% \mathrm{CI})=1.015(1.003-1.026) ; \mathrm{p}=0.012)$. The magnitude of the influence was $62.9 \%$. On day3, Anxiety level and PLR had a significant influence on the incidence of severe COVID-19 $($ respectively OR $(95 \% \mathrm{CI})=1.010(1.044-1.436) ; \mathrm{p}=0.013$ and $\mathrm{OR}(95 \% \mathrm{CI})=1.225(1.002-$ $1.019) ; \mathrm{p}=0.019)$. The magnitude of the influence was $63.0 \%$.

\section{DISCUSSION}

More than half of the research subjects were overweight and obese. Obesity is often associated with disorders of the HPA axis. However, it is still unclear whether obesity causes HPA axis disorders or HPA axis disorders cause obesity. Obesity can cause an increase in cortisol levels triggered by prolonged stress, which in turn results in the accumulation of adipose tissue and weight gain. However, when the study was conducted in the chronically stressed group, it was found that the HPA axis was hypoactive in patients with abdominal obesity ${ }^{24}$. In addition, there was an increased risk of experiencing a more severe disease of COVID-19 and increased risk of hospitalization and intensive care in obese patient groups ${ }^{25,26}$. Mechanisms that can explain the relationship between obesity and the risk of critical illness in COVID-19 are: changes in the physiology of the respiratory system, chronic inflammation, impaired pulmonary perfusion, endocrine dysfunction, comorbid complications, and dysregulation of the immune system ${ }^{27,28}$.

In this study, mortality was experienced by 1 subject. The subject experienced a decrease in condition after the 3rd day of treatment, then endotracheal intubation was performed. Subject had an increase in scores of depression, anxiety, stress (DASS-21), RPL, and salivary cortisol levels in line with the worsening of the clinical condition. It was in contrast to most of the 
subjects who experienced an improvement in clinical condition and all parameters which measured.

Majority of subject had a high anxiety level on day-0. Depression, anxiety, and stress level were going down on day-3 and 6. This phenomenon showed the stress response and coping mechanism of the patient. A person who was diagnosed with confirmed COVID-19 and must be treated in a special isolation room is a stressor condition. This condition will trigger a primary assessment process in which individuals will assess the threat level of a condition in relation to well-being. When an event is assessed as a threat or challenge, the secondary assessment process provides a global assessment of resources and capabilities to manage the threat. Socio-cultural factors (such as: social and family support, interpersonal relationships), emotional (spirituality/religiosity, purpose in life, motivation), cognitive (awareness, intuition, intelligence, problem solving skills, reflection, attachment, and education levels), and physical conditions (physical illness, drugs consumed) can affect the process of coping mechanisms ${ }^{29,30}$. Coping mechanisms are expected to bring individuals to adapt and create conditions of eustress (stress resolved). In this study, most of the patients had a lower DASS-21 score and severity of COVID19 on day-6. This condition can indicate that the research subjects are able to cope with stressors and followed by improvement of clinical condition. On the other hand, the majority of patients in this study had mild to moderate severity and clinical improvement was noted during treatment. This condition showed the immune system was still able to overcome the infection. Improvement of the patient's physical condition could also affect the reduction of stress levels.

There was a significant lower levels of salivary cortisol in the severe COVID-19 group compared to mild-moderate group on day 0 . In a previous study conducted in China, it was found that the cortisol levels of critically ill patients due to COVID-19 were lower than those of nonCOVID-19 critically ill patients. Two-thirds of critically ill patients with COVID-19 have a plasma cortisol value of $<10 \mu \mathrm{g} / \mathrm{dl}$, which is a diagnostic criteria for Critical Illness Related Corticosteroid Insufficiency (CIRCI) ${ }^{31}$. In Alzahrani et al. study, 32\% of the COVID-19 subjects were included in the low cortisol category. In addition, there was also a negative relationship between ACTH and blood cortisol levels with severity, the lower the ACTH and cortisol levels, the higher the disease severity ${ }^{32}$.

This opposite relationship is associated with the suspicion that the SARS-CoV-2 virus attacks the adrenal cortex, which produces cortisol. In a postmortem study of severe COVID-19 patients, almost half of the patients had adrenal gland lesions ${ }^{31,33}$. In addition to structural changes in the adrenal glands of COVID-19 patients, another hypothesis that influences the HPA axis in COVID-19 is molecular mimicry of the SARS-CoV-2 virus with ACTH. The immune system will attack endogenous ACTH which further decreases the production of cortisol ${ }^{34,35}$. More than half of the subjects were overweight and obese. In patients with chronic stress and obesity, the HPA axis is hypoactive so that cortisol levels are also lower ${ }^{24,34,36}$.

In previous studies, platelets and lymphocytes were associated with the severity of COVID-19. Lymphopenia is almost always found in severe cases (associated with an increase in cytokine production) ${ }^{11}$. Several suspected mechanisms of lymphopenia are lymphocyte 
exhaustion due to repeated $\mathrm{T}$ cell stimulation, $\mathrm{T}$ cell apoptosis, and direct infection of lymphocytes by the SARS-CoV-2 virus ${ }^{37,38}$. Thrombocytopenia was seen in one third of patients with COVID-19. Some of the mechanisms of thrombocytopenia are direct infection of the bone marrow and inhibition of platelet synthesis, destruction of platelets due to the immune system, and platelet aggregation in the lung resulting in microthrombus and platelet consumption ${ }^{39,40}$. In the study, it was found that the decrease in lymphocytes was more than the platelets, so the PLR was increased. Thrombocytopenia was not found in most of the study subjects. Most of the subjects included had mild to moderate severity.

The results of this study are similar to those of previous studies. Patients with severe degrees had a higher RPL than those with mild degrees. In addition, RPL also describes disease progression and prognosis of the disease ${ }^{41,42}$.

There were some limitations of this study. This study included non-critical patients, related to the DASS-21 questionnaire. It could not describe the complete spectrum of the variables at various levels of COVID-19 severity. Stress levels in the previous period were not assessed. Chronic stress factors can affect the HPA axis and the patient's salivary cortisol levels. Corticosteroid therapy as one of the therapies given to patients confound the results of salivary cortisol levels.

\section{CONCLUSION}

Level of depression, anxiety, and stress of COVID-19 patients was quite high (especially anxiety) on day 0 of hospitalization. Overall DASS-21 score decreased on the $6^{\text {th }}$ day of hospitalization. Salivary cortisol was lower in the severe group on day 0. PLR on days 0 and 3 and anxiety level on day 3 were independent factors related to the severe case of COVID-19. severity. Improvements in all variables were in line with the decreasing severity of COVID-19, although non statistically significant.

\section{REFERENCES}

1. De Gaudio AR, Bonifazi M, Romagnoli S. The Stress Response of Critical Illness: Which Is the Role of Sedation? In: De Gaudio AR, Romagnoli S, editors. Critical Care Sedation. Springer; 2018. p. 9-18.

2. Marik PE. Endocrinology of the Stress Response During Critical Illness. In: Ronco C, Bellomo R, Kellum JA, Ricci Z, editors. Critical Care Nephrology. Third Edit. Elsevier; 2019. p. 446-54.

3. McEwen BS. Basic mechanisms of, and treatment targets for, stress- related disorders. In: Geddes JR, Andreasen NC, Goodwin GM, editors. New Oxford Textbook of Psychiatry. Third Edit. Oxford University Press; 2020. p. 829-39.

4. Russ TC, Stamatakis E, Hamer M, Starr JM, Kivimäki M, Batty GD. Association between psychological distress and mortality: Individual participant pooled analysis of 10 prospective cohort studies. BMJ. 2012;345(7871).

5. Nielsen NR, Kristensen TS, Schnohr P, Grønbæk M. Perceived stress and cause-specific mortality among men and women: Results from a prospective cohort study. Am J Epidemiol. 2008;168(5):481-91.

6. American Psychiatric Association. DSM-5 Diagnostic Classification. In: Diagnostic and Statistical Manual of Mental Disorders. Fifth Edit. 2013. 
7. $\mathrm{Hu}$ Y, Chen Y, Zheng Y, You C, Tan J, Hu L, et al. Factors related to mental health of inpatients with COVID-19 in Wuhan, China. Brain Behav Immun. 2020;89(July):587-93.

8. Sani G, Janiri D, Di Nicola M, Janiri L, Ferretti S, Chieffo D. Mental health during and after the COVID-19 emergency in Italy. Psychiatry Clin Neurosci. 2020;74(6):372.

9. Duplessis C, Rascona D, Cullum M, Yeung E. Salivary and free serum cortisol evaluation. Mil Med. 2010;175(5):340-6.

10. Bozovic D, Racic M, Ivkovic N. Salivary cortisol levels as a biological marker of stress reaction. Med Arh. 2013;67(5):374-7.

11. Liu J, Li S, Liu J, Liang B, Wang X, Wang H, et al. Longitudinal characteristics of lymphocyte responses and cytokine profiles in the peripheral blood of SARS-CoV-2 infected patients. EBioMedicine. 2020;55(December 2019).

12. Yang X, Yang Q, Wang Y, Wu Y, Xu J, Yu Y, et al. Thrombocytopenia and its association with mortality in patients with COVID-19. J Thromb Haemost. 2020;18(6):1469-72.

13. Choi J, Fauce SR, Effros RB. Reduced telomerase activity in human T lymphocytes exposed to cortisol. Brain Behav Immun. 2008;22(4):600-5.

14. Nakagami H. Cellular senescence and senescence-associated $\mathrm{T}$ cells as a potential therapeutic target. Geriatr Gerontol Int. 2020;20(2):97-100.

15. Wittstein IS. Editorial: Depression, anxiety, and platelet reactivity in patients with coronary heart disease. Eur Heart J. 2010;31(13):1548-50.

16. Mazza MG, Lucchi S, Tringali AGM, Rossetti A, Botti ER, Clerici M. Neutrophil/lymphocyte ratio and platelet/lymphocyte ratio in mood disorders: A meta-analysis. Prog NeuroPsychopharmacology Biol Psychiatry. 2018;84:229-36.

17. Hu J, Zhou W, Zhou Z, Han J, Dong W. Elevated neutrophil-to-lymphocyte and platelet-to-lymphocyte ratios predict post-stroke depression with acute ischemic stroke. Exp Ther Med. 2020;19:2497-504.

18. Cuesta JM, Singer M. The stress response and critical illness: A review. Crit Care Med. 2012;40(12):3283-9.

19. Lovibond SH, Lovibond PF. Manual for the Depression Anxiety Stress Scales. Psychology Foundation of Australia. 1995.

20. Tran TD, Tran T, Fisher J. Validation of the depression anxiety stress scales (DASS) 21 as a screening instrument for depression and anxiety in a rural community-based cohort of northern Vietnamese women. BMC Psychiatry. 2013 Dec 12;13(1):24.

21. Damanik ED. The Measurement of Reliability, Validity, Items Analysis and Normative Data of Depression Anxiety Stress Scale (DASS). J Psikol Univ Indones. 2011;

22. Salimetrics. High Sensitivity SALIVARY CORTISOL [Internet]. Salimetrics. Salimetrics; 2014. 1-21 p. Available from: https://www.salimetrics.com/assets/documents/1-3002.pdf

23. World Health Organization. Clinical management of COVID-19: Interim Guidance. World Health Organization; 2020.

24. Rodriguez ACI, Epel ES, White ML, Standen EC, Seckl JR, Tomiyama AJ. Hypothalamicpituitary-adrenal axis dysregulation and cortisol activity in obesity: A systematic review. Psychoneuroendocrinology. 2015;62:301-18.

25. Ho JSY, Fernando DI, Chan MY, Sia CH. Obesity in COVID-19: A Systematic Review and Metaanalysis. Ann Acad Med Singapore. 2020;49(12):996-1008.

26. Gao M, Piernas C, Astbury NM, Hippisley-Cox J, O'Rahilly S, Aveyard P, et al. Associations between body-mass index and COVID-19 severity in 6.9 million people in England: a prospective, community-based, cohort study. Lancet Diabetes Endocrinol. 2021;9(6):350-9.

27. Korakas E, Ikonomidis I, Kousathana F, Balampanis K, Kountouri A, Raptis A, et al. Obesity and COVID-19: Immune and metabolic derangement as a possible link to adverse clinical outcomes. Am J Physiol - Endocrinol Metab. 2020;319(1):E105-9.

28. Kwok S, Adam S, Ho JH, Iqbal Z, Turkington P, Razvi S, et al. Obesity: A critical risk factor in the COVID -19 pandemic . Clin Obes. 2020;10(6):1-11. 
29. Goh YW, Sawang S, Oei TPS. The Revised Transactional Model (RTM) of Occupational Stress and Coping: An Improved Process Approach. Aust New Zeal J Organ Psychol. 2010 Apr 1;3:1320.

30. Hudson K. Coping Complexity Model: Coping Stressors, Coping Influencing Factors, and Coping Responses. Psychology. 2016;07(03):300-9.

31. Mao Y, Xu B, Guan W, Xu D, Li F, Ren R, et al. The Adrenal Cortex, an Underestimated Site of SARS-CoV-2 Infection. Front Endocrinol (Lausanne). 2021;11(January):1-10.

32. Alzahrani AS, Mukhtar N, Aljomaiah A, Aljamei H, Bakhsh A, Alsudani N, et al. The Impact of COVID-19 Viral Infection on the Hypothalamic-Pituitary-Adrenal Axis. AACE Endocr Pract. 2021;27(2):83-9.

33. Santana MF, Borba MGS, Baía-Da-Silva DC, Val F, Alexandre MAA, Brito-Sousa JD, et al. Case report: Adrenal pathology findings in severe COVID-19: An autopsy study. Am J Trop Med Hyg. 2020;103(4):1604-7.

34. Lamontagne SJ, Pizzagalli DA, Olmstead MC. Does inflammation link stress to poor COVID-19 outcome? Stress Heal. 2021;37(3):401-14.

35. Wheatland R. Molecular mimicry of ACTH in SARS - Implications for corticosteroid treatment and prophylaxis. Med Hypotheses. 2004;63(5):855-62.

36. Miller GE, Chen E, Zhou ES. If it goes up, must it come down? Chronic stress and the hypothalamic-pituitary-adrenocortical axis in humans. Psychol Bull. 2007;133(1):25-45.

37. Fathi N, Rezaei N. Lymphopenia in COVID-19: Therapeutic opportunities. Cell Biol Int. 2020;44(9):1792-7.

38. Xu H, Zhong L, Deng J, Peng J, Dan H, Zeng X, et al. High expression of ACE2 receptor of 2019nCoV on the epithelial cells of oral mucosa. Int J Oral Sci. 2020;

39. Guan W, Ni Z, Hu Y, Liang W, Ou C, He J, et al. Clinical Characteristics of Coronavirus Disease 2019 in China. N Engl J Med. 2020 Apr 30;382(18):1708-20.

40. Xu P, Zhou Q, Xu J. Mechanism of thrombocytopenia in COVID-19 patients. Ann Hematol. 2020;99(6):1205-8.

41. Qu R, Ling Y, Zhang Y hui zhi, Wei L ya, Chen X, Li X mian, et al. Platelet-to-lymphocyte ratio is associated with prognosis in patients with coronavirus disease-19. J Med Virol. 2020;92(9):1533-41.

42. Chan AS, Rout A. Use of Neutrophil-to-Lymphocyte and Platelet-to- Lymphocyte Ratios in COVID-19. J Clin Med. 2020;12(7):448-53. 